\title{
Computational Prediction of mi RNA in Measles virus Project Report
}

\author{
*Nivruti B. Panchal, Sagar K. Patel, Krupa K. Patel, \\ Mr. Nutan Prakash Vishvakarma \\ Corresponding Author: Nivruti B. Panchal
}

\begin{abstract}
RNA is small, single-stranded RNA which is found in viruses as well as in animals. The role of microRNAs at the post-transcriptional regulation has been reported in plants, animals and viruses. During viral infection, miRNAs plays role in host and pathogen interaction thus playing major role in pathogenesis. In the current work, we have used computational approach to analyze Measles virus genome. Pre-miRNA were predicted with the help of VMir software. The prediction of real and pseudomiRNA were done with the help of $n c R N A$ seq. tool. Here total 5 novel miRNAs have been predicted. These findings will provide a reference point for further study on miRNA identification and broaden the understanding of genome in Measles.
\end{abstract}

KEY WORDS: Measles Virus, Microrna, In Silico Prediction, Comparative Genomics

Date of Submission: 19-06-2017

Date of acceptance: 22-07-2017

\begin{tabular}{|l|l|}
\multicolumn{1}{|c|}{ Lbbreviation } & \\
\hline miRNA & Micro RNA \\
\hline UTR & Untranslated region \\
\hline NCBI & National Centre for biotechnological information \\
\hline FASTA & Fast all \\
\hline MR & Reverse \\
\hline
\end{tabular}

\section{Introduction}

MicroRNA was first identified in nematode cell also it is expressed by all metazoans, plants, and many viruses too. MicroRNA can be defined as the small non-coding RNAs that play regulatory role in numerous and diverse cellular processes such as immune function, apoptosis, stress responses, homeostasis and tumor genesis. There are various miRNA those are found in extracellular region including various biological fluids. Therefore, they are known as circulating miRNA or extracellular miRNA. MiRNAs corresponds the small interfering RNAs (siRNAs) of the RNA interference (RNAi) pathway, except miRNAs evolve from regions of RNA transcripts that fold back on themselves to form short hairpins, whereas siRNAs excogitate from longer regions of double-stranded RNA. The first human disease associated with deregulation of miRNAs was chronic lymphocytic leukemia. Other B cell malignancies followed. As much as $40 \%$ of miRNA genes may lie in the introns of protein and non-protein coding genes or even in exons of long nonprotein-coding transcripts So far 24521 miRNA have been identified from plant animal and virus species. Their target genes include tumor suppressor genes and oncogenes, and by regulating the expression of these pivotal genes, microRNAs have important roles in the mediation of tumor progression. Most of the microRNA is of 22 nucleotide. It affects mainly on the biochemical processes. Those miRNA which attack the host cell it can be plant, animal, viruses by using the host machinery instead of its own machinery. MiRNAs are short $22 \pm 3$ nucleotide RNA molecules that post transcriptionally regulate gene expression by binding to 3 '-untranslated regions (3'UTR) of target mRNAs, thereby inducing translational silencing and/or transcript degradation. ${ }^{1}$ There is various activity of viral microRNA like Auto regulation of viral gene expression, Avoidance of host defenses, maintaining latent and persistent infection. Viral miRNAs can coordinate both cellular as well as viral gene expressions through the regulation of cellular elements involved antiviral responses, exhilarating cellular miRNAs, or targeting their own viral messenger RNAs to modulate the viral replication cycle. Initial mechanism of cellular miRNA occurs in the nucleus suggesting that only viruses that replicate in nucleus are able to generate miRNA. More than 60 viral miRNAs have been analyzed within four different virus families. Most of the reported virus concealed miRNAs are reported from Herpesvirues and small number within Adenovirus (1), Retrovirus (1) and Polyomavirus (1) families. Measles virus (MeV) is a single-stranded, negative-sense, enveloped (nonsegmented) RNA virus of the genus morbillivirus within the family Paramyoxviridae. Humans are the natural anchor person of the virus; no animal accumulation are known to exist. The measles virus is the cause of 
measles, an infection of the respiratory system. Symptoms include cough, fever, runny nose, red eyes and a generalized, maculopoagulor erythematous rash. Measles is an airborne disease which spreads easily through the coughs and sneezes of those infected. It may also be spread through contact with spittle or nasal secretions. Nine out of ten people who are not immune and share living space with an infected person will catch it. the measles vaccine is effective at preventing the disease. Vaccination has resulted in a 70\% decrease in deaths from measles between 2000 and 2013 with about $90 \%$ of children universally being currently vaccinated. No specific treatment is available. Abetting bother may improve outcomes.This may include giving oral restotration (slightly sweet and salty fluids), healthy food, and medications to control the fever. Antibiotics may be used if a secondary bacterial infection such as pneumonia occurs. Nutriment supplementation is also recommended in the developing world. There is no specific treatment for measles. Most people with painless measles will recover with rest and complementary treatment.

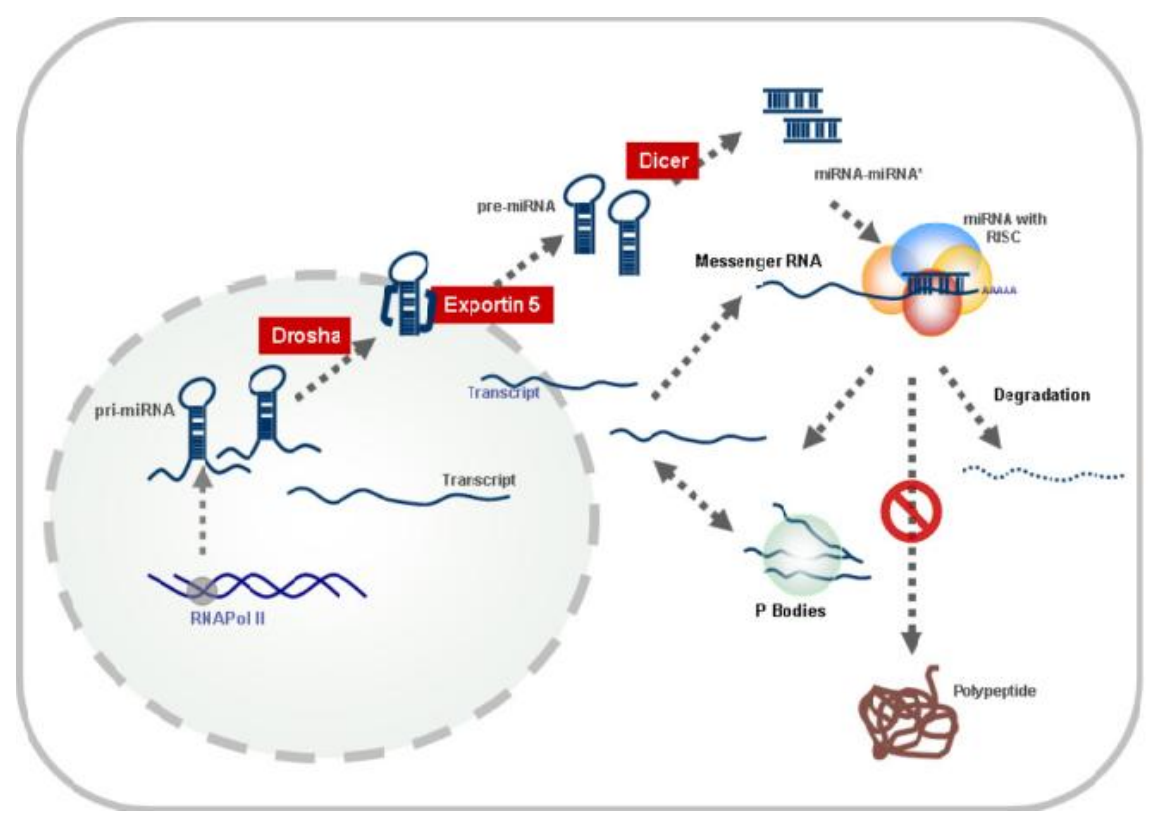

(A.)

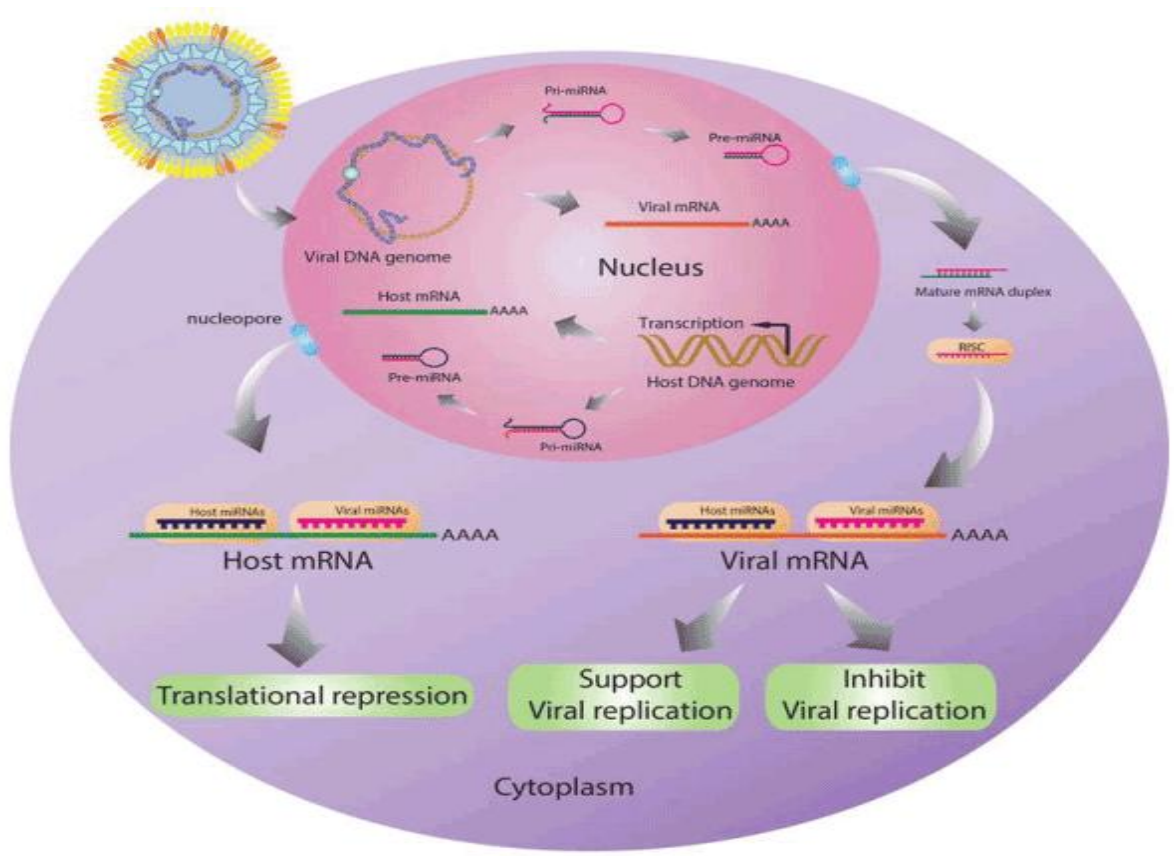

(B.)

Fig 1: Biogenesis of miRNA in virus 


\section{Used Software:}

\section{Materials And Method}

\section{NCBI:}

The National Center for Biotechnology Information (NCBI) is part of the United States National Library of Medicine (NLM), a branch of the National Institutes of Health. The NCBI is located in Bethesda, Maryland and was founded in 1988 through legislation sponsored by Senator Claude Pepper. NCBI is directed by David Lipman, one of the original authors of the BLAST sequence alignment program and a widely respected figure in bioinformatics. He also leads an intramural research program, including groups led by Stephen Altschul (another BLAST co-author), David Landsman, Eugene Koonin (a prolific author on comparative genomics), John Wilbur, Teresa Przytycka, and Zhiyong Lu.

NCBI is listed in the Registry of Research Data Repositories re3data.org.

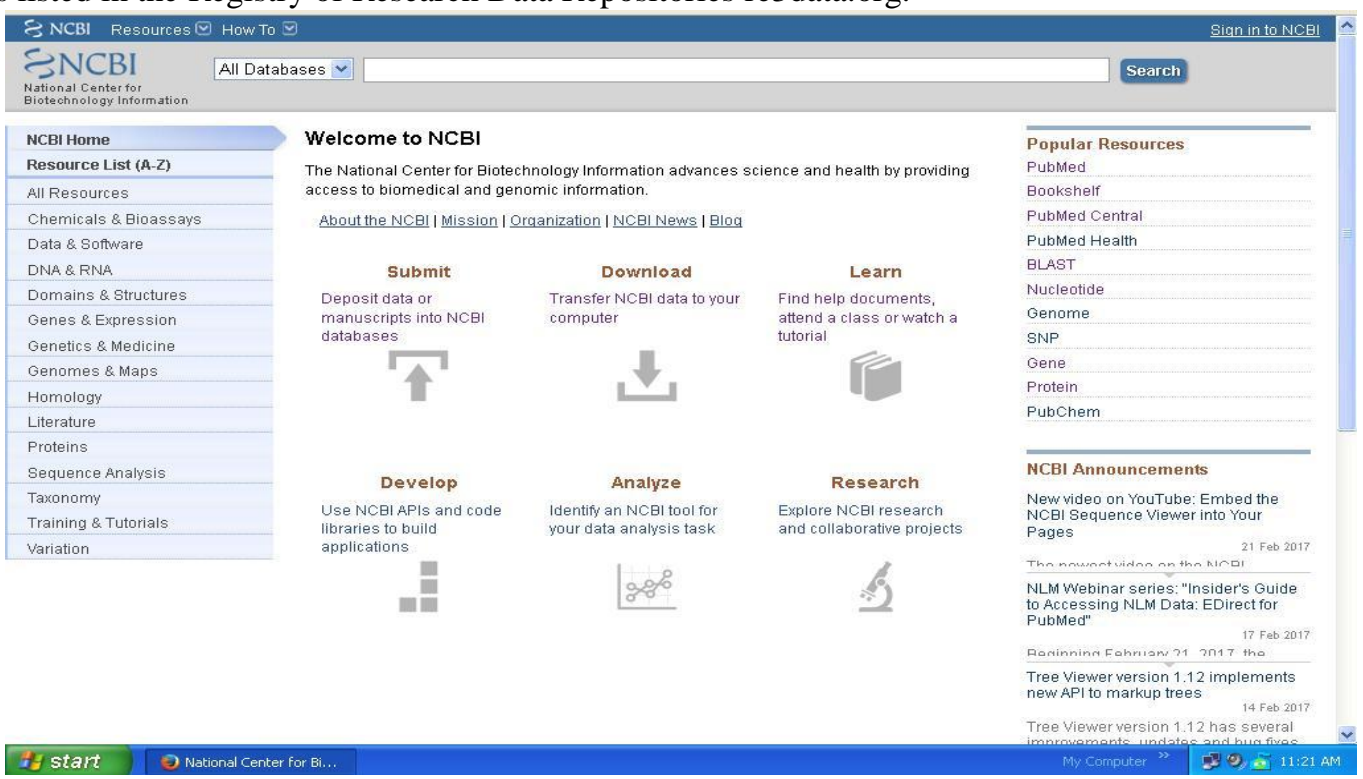

Fig 2: Homepage of NCBI

\section{Vmir Analyzer:}

Vmir analyzer: The miRNA prediction method described here requires the VMir software package and one or more files containing the genomic sequences to be analyzed; the latter may be in raw text, FASTA or GenBank format. The latest version of the VMir software (v1.5 as of the time of this writing) can be downloaded from the following URL: http://www.hpi-hamburg.de/research/departments-andresearchgroups/antiviral-defense-mechanism/software-download.html. To install the software, you will need a computer running a Windows operating system; the software will not run on Linux or MacOS systems. The VMir package also requires the Microsoft .NET Framework v2.0 or higher; in case your machine does not already have the framework, it will be installed automatically during the setup process. Unzip/extract the downloaded software archive to a folder on your hard drive and click the Setup.exe file, then follow the instructions provided on the screen. This will install two programs: Vmir Analyzer (which performs the actual analysis).

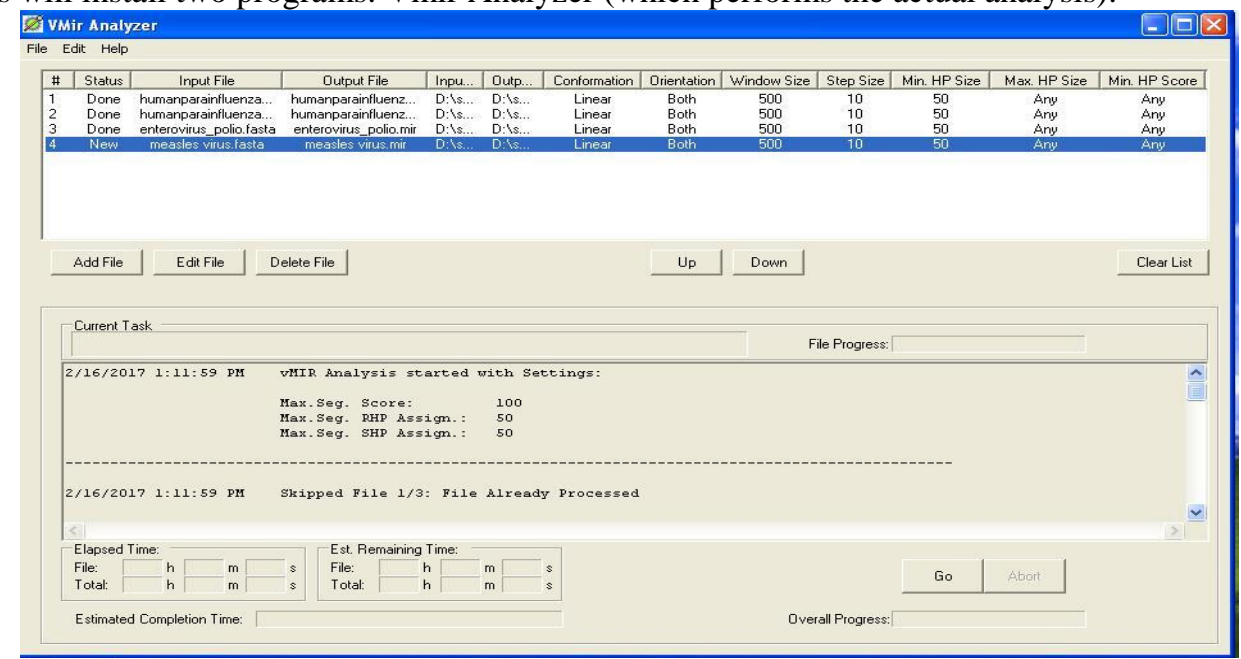

Fig 3: Homepage of Vmir analyzer 


\section{Vmir viewer:}

VMir Viewer (which allows viewing of results files written by VMir Analyzer). You can start both programs from the "VMir" folder located in the Programs folder of your Start Menu. You will also find shortcuts to the program's documentation in this folder. It helps us the view the primary screened miRNAs of the $\mathrm{MeV}$ through the VMir Analyzer.

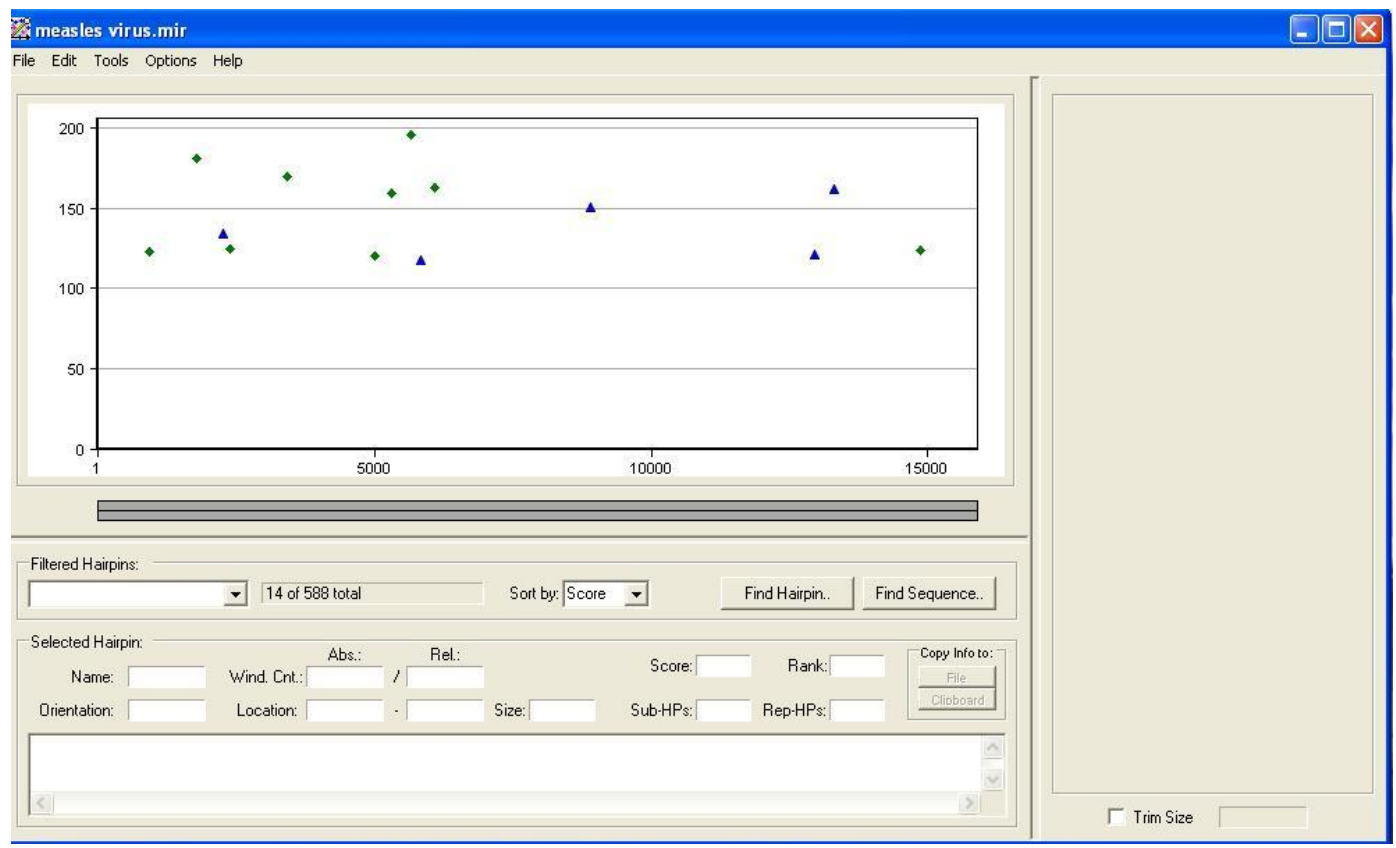

\section{MFOLD:}

Fig 4: Homepage of Vmir viewer

The mfold web sever is one of the oldest web servers in computational molecular biology. It has been in continuous operation since the fall of 1995 when it was introduced at Washington University's school of Medicine. It operated at Rensseler polytechnic Institute from October 2000 to November 5, 2010, when it was relocated to the RNA Institute web site. As of the relocation date, an article describing it that was published in the first web server issue of Nucleic Acids Research in July 2003 had been cited 2893 times. In October 2005, in -cites ranked this article number 3 in a list of 103 "super-hot papers" in science published since 2003.

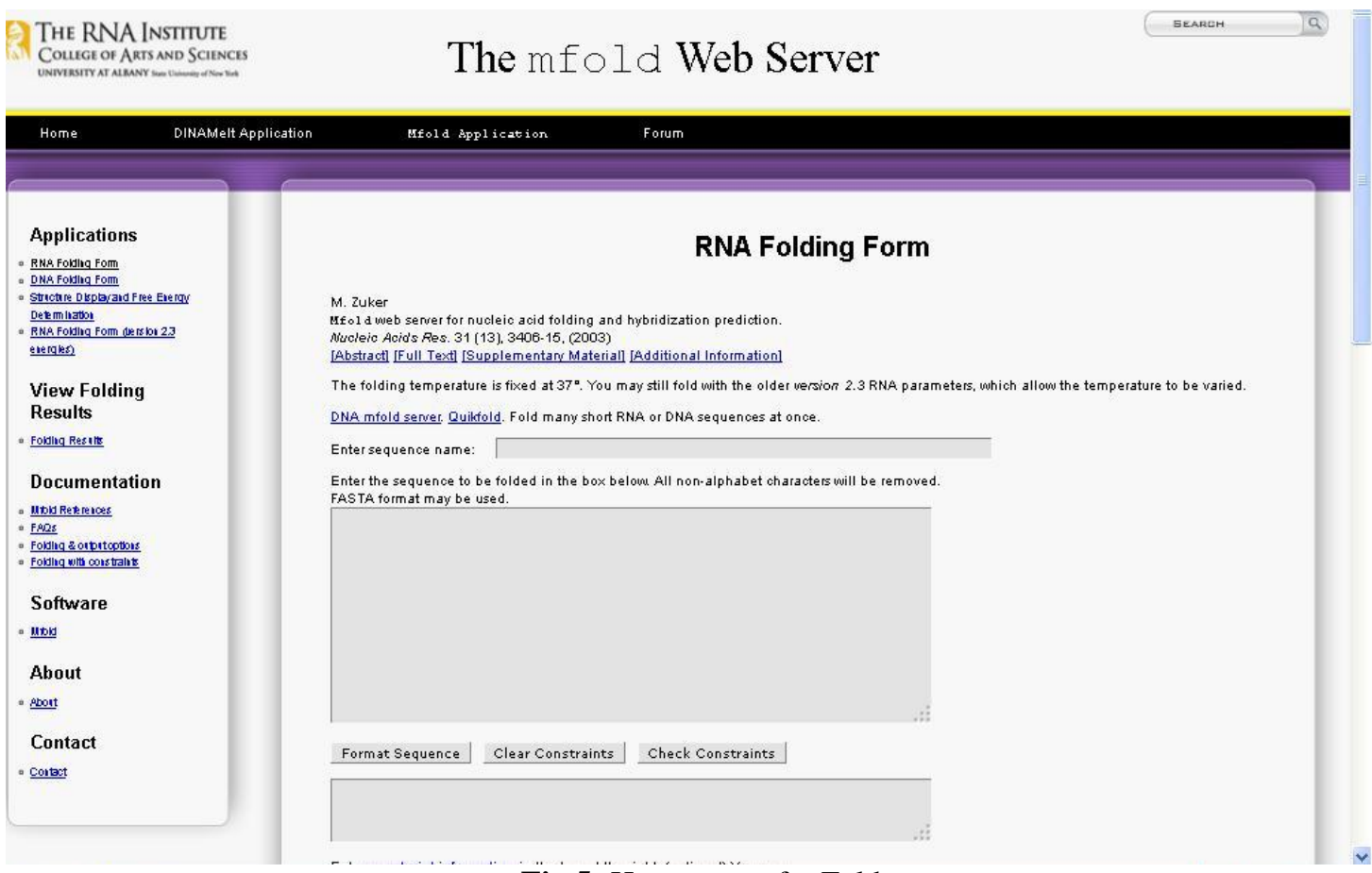

Fig 5: Homepage of mFold 


\section{MatureBayes:}

MatureBayes offers two alternatives for computing the most probable start position of the mature miRNA(s) in any given miRNA precursor. If the stem that produces a mature miRNA (or functional stem) is known, then the proposed computational truth is the top scoring candidate produced by the classifier for that specific stem. The complementary stem is not considered in this case. Alternatively, if the functional stem is not known, the proposed computational truth is the duplex formed by the top scoring candidate estimated over both stems, along with its miRNA*.

\section{MatureBayes \\ \{.్య For more Tools, please use our main Tool Website: mirna.imbb.forth.gr}

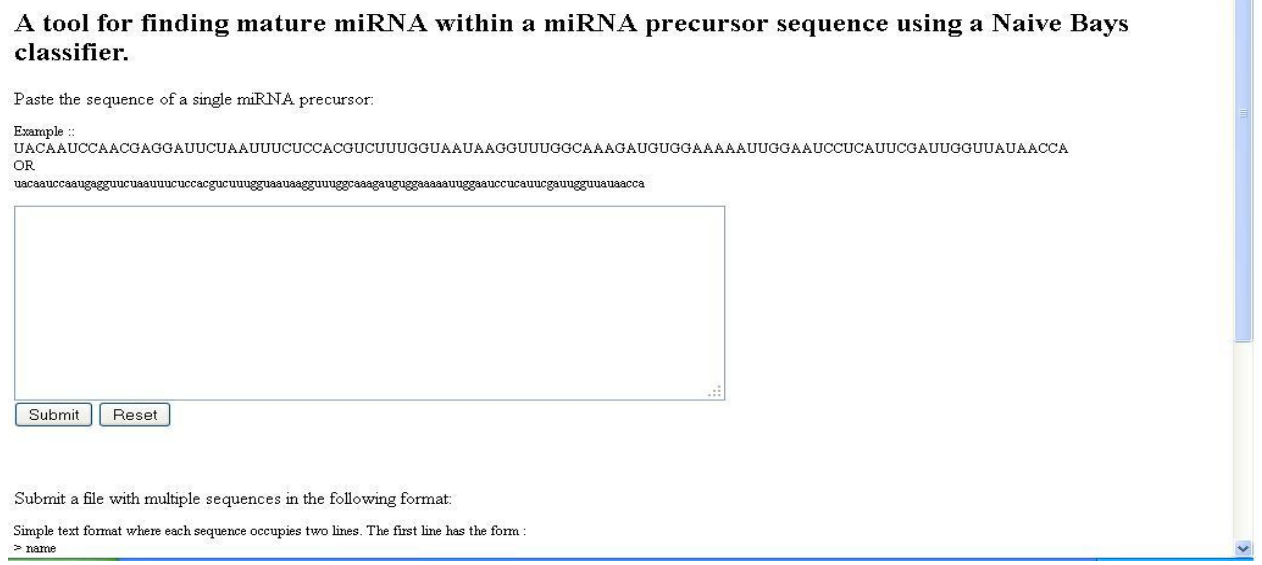

Fig 6: Homepage of MatureBayes

\section{Methods}

1. We used the NCBI tool to search various genomes of various species. We proceeded with measles virus genome.After gaining the sequence we converted it into FASTA format.

2. We then analyzed the sequence using a tool Vmir analyzer.

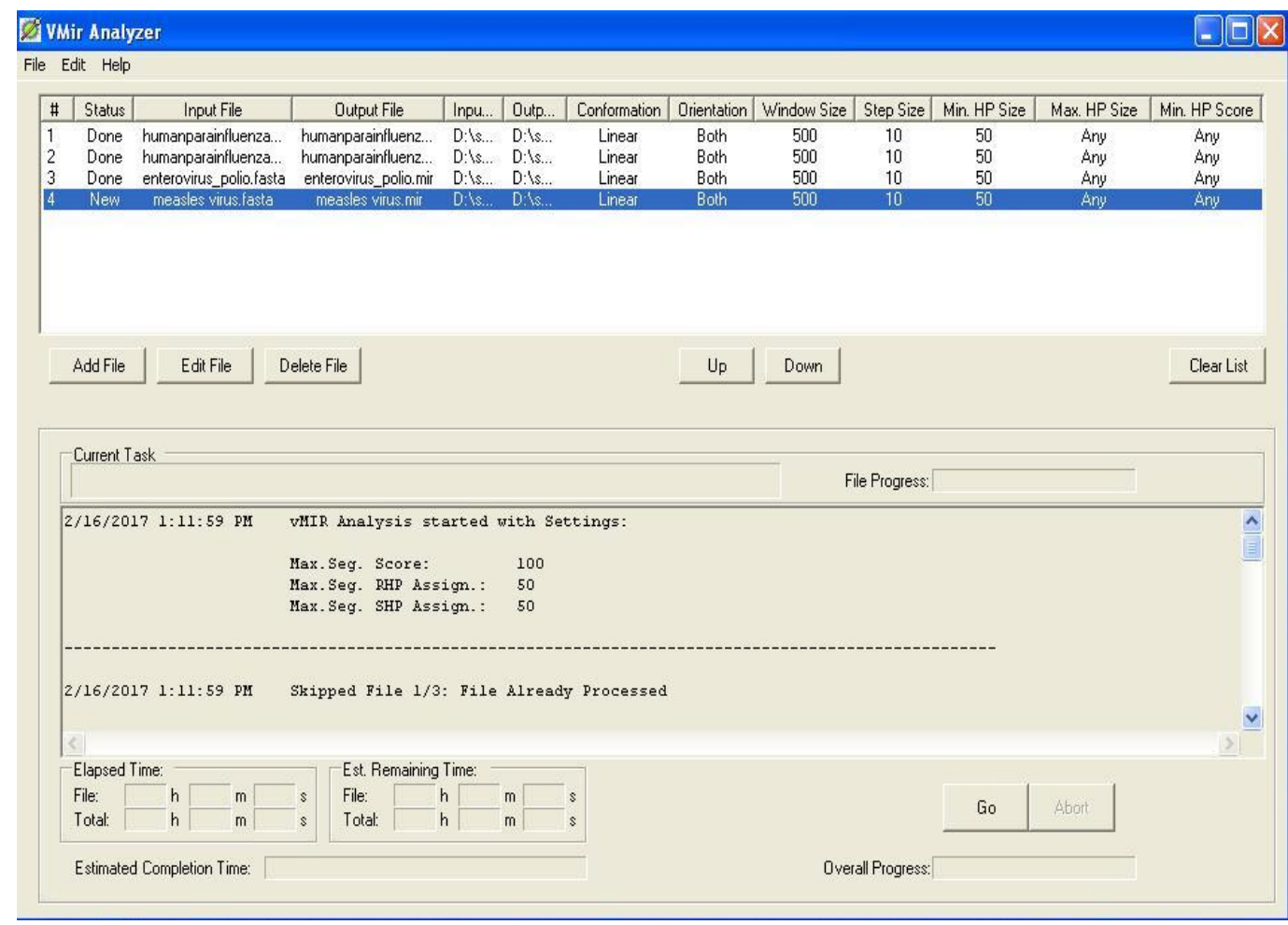

Fig 7: Vmir analyzer of measles 
3. We interpreted the results using another tool.

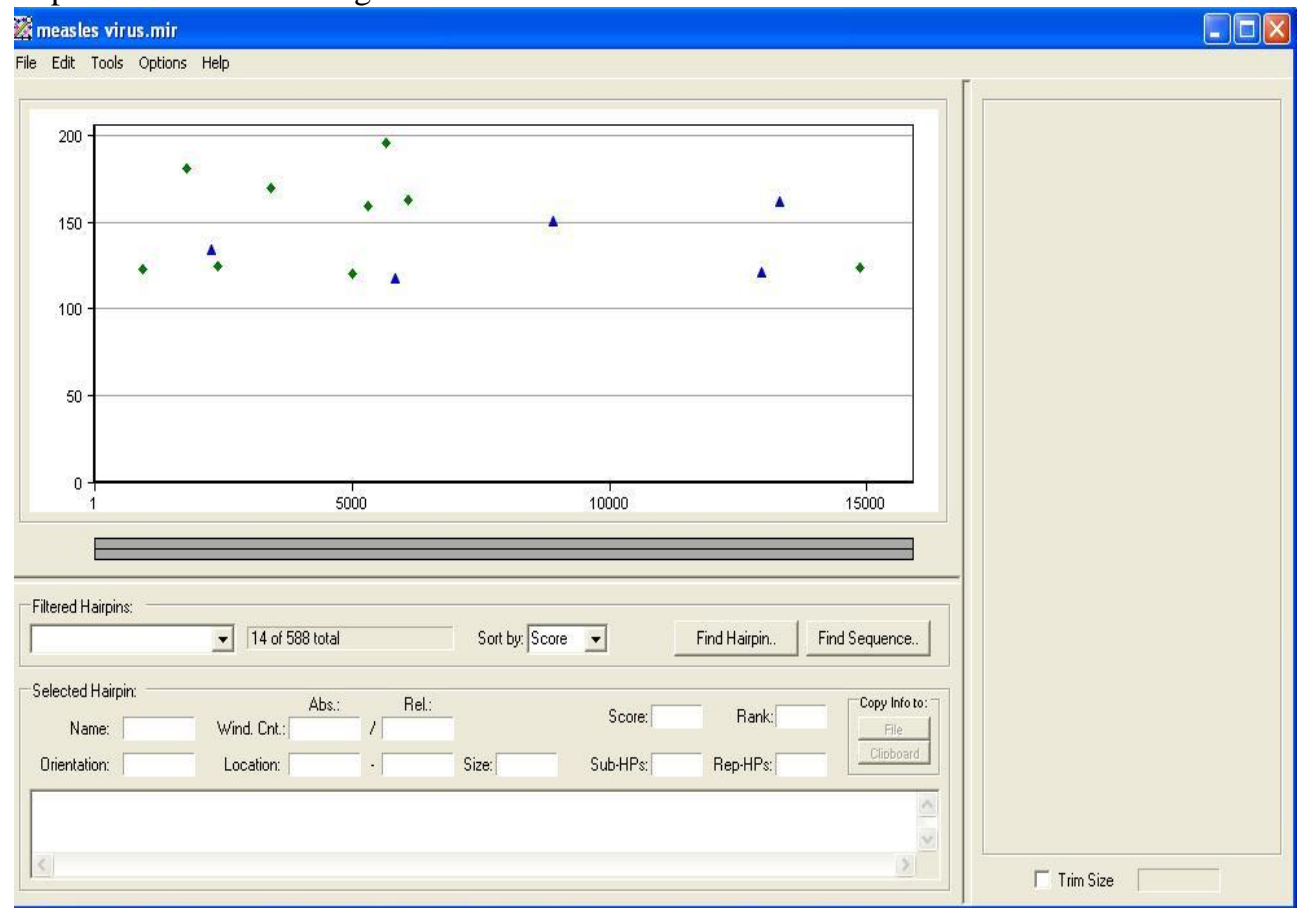

Fig 8: Vmir viewer of measles

4. Primary sequence is obtained. Further Pri-sequence was screened using ncRNA seq. tool.

5. Pseudo miRNA \& miRNA gained

6. Collect the miRNA seq. in FASTA format

7. Tabulate miRNA seq. using matureBayes $®$.

\section{MatureBayes}

\section{For more Tools, please use our main Tool Website: mirna.imbb.forth.gr}

A tool for finding mature miRNA within a miRNA precursor sequence using a Naive Bays classifier.

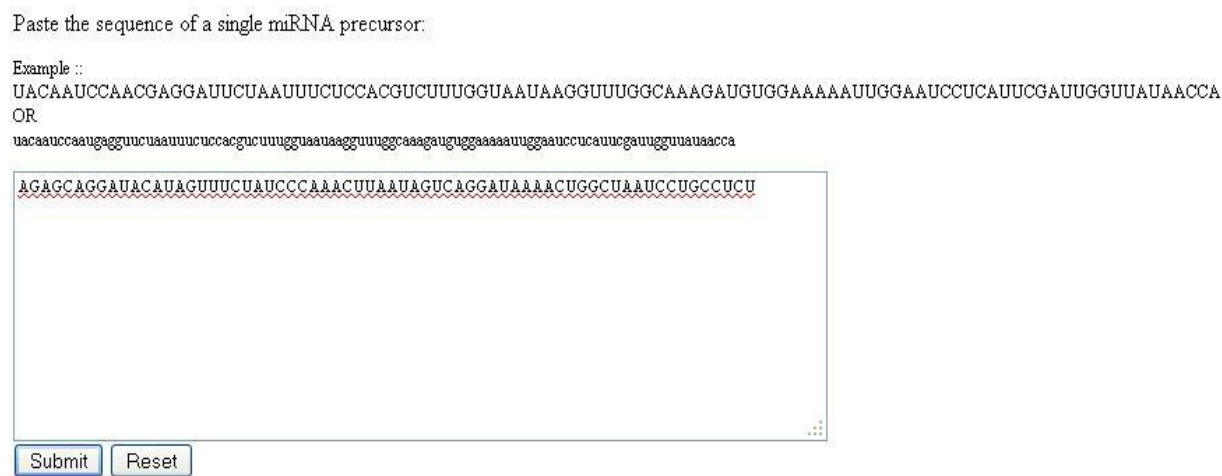

\section{Submit a file with multiple sequences in the following format:}

Simple text format where each sequence occupies two lines. The first line has the form :

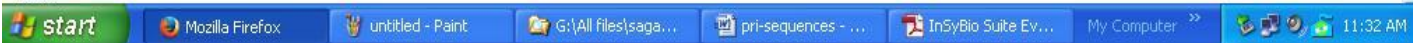

Fig 9: Sequence of measles in matureBayes

8. Pre-seq. is folded using $\mathrm{mFold} \circledast$ tool. 


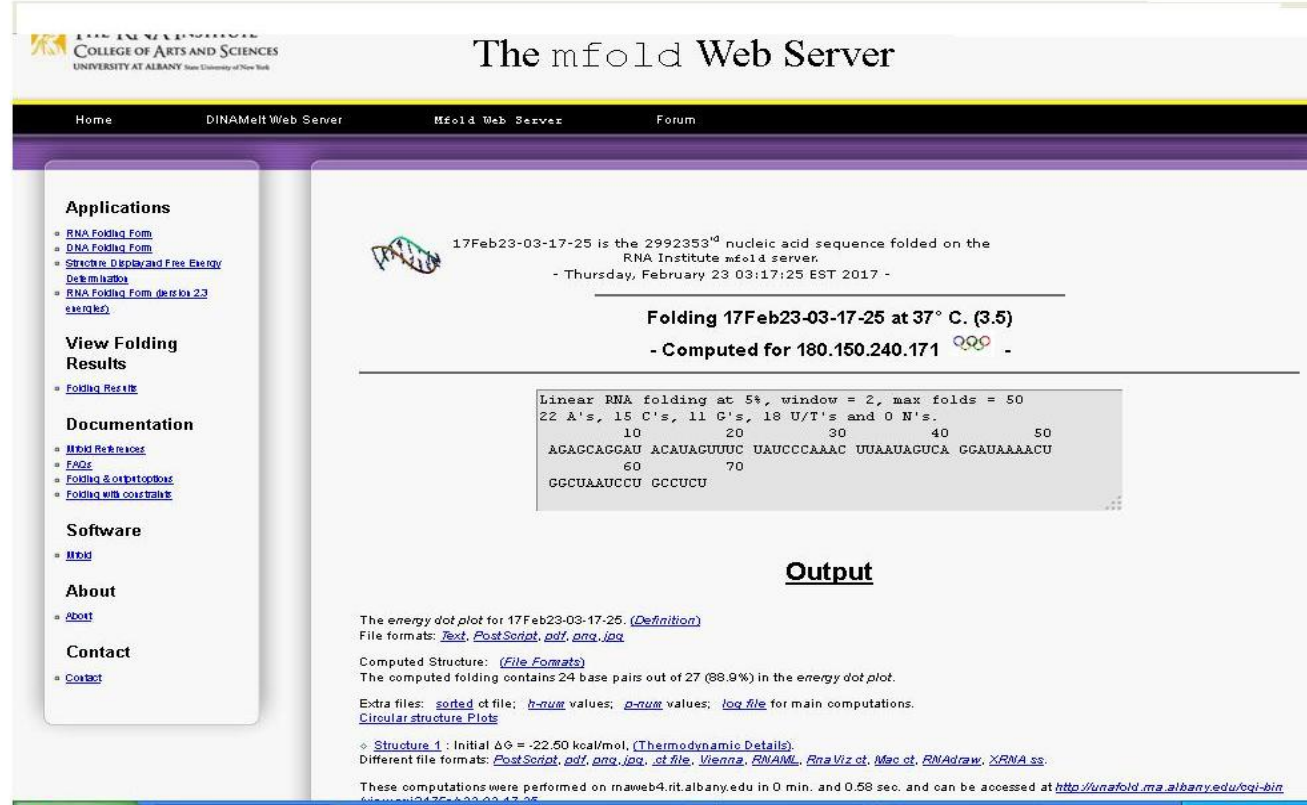

Fig 10: mfold of measles virus genome

\section{Result And Discussion}

We used improved integrated computational approach to obtain the sequence of measles virus in order to identify miRNA present in it. As a result, a total of 5 novel miRNA were identified from 15 hairpin loop candidates. The miRNA were analyzed using Vmir analyzer, interpreted through Vmir viewer and screened Precursor miRNA using ncRNAsequence tool and tabulation was done by Mature Bayes.

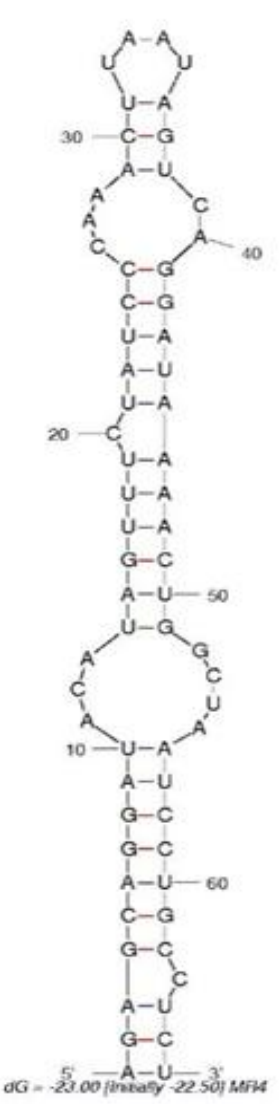

MR4

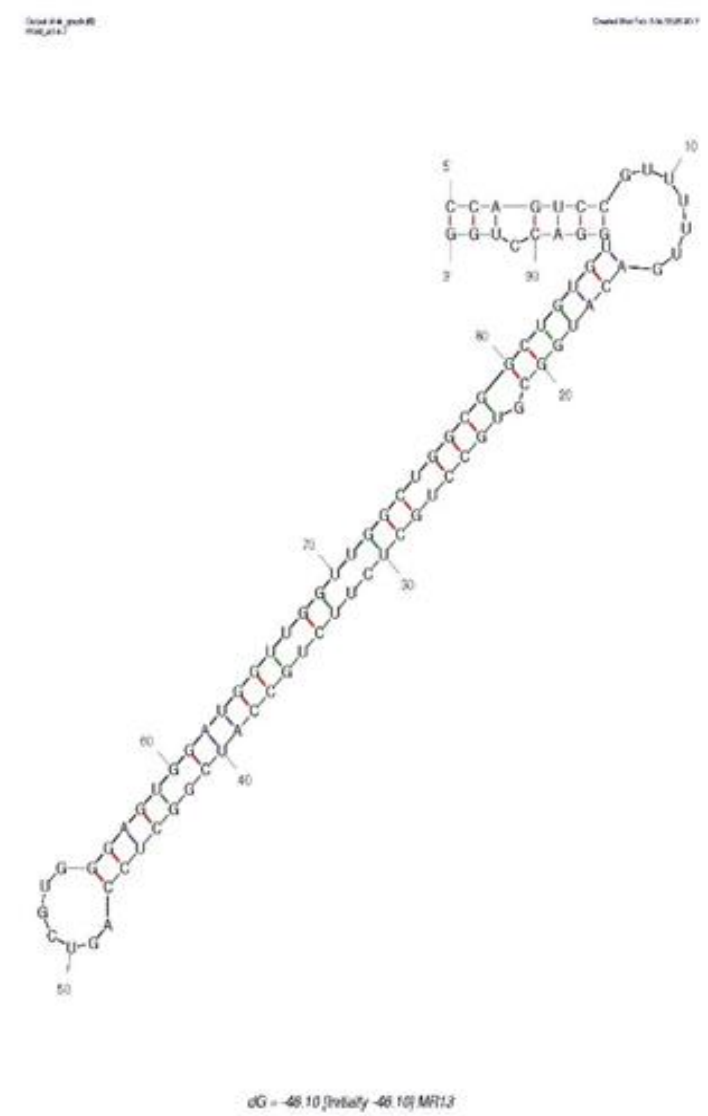

MR13 


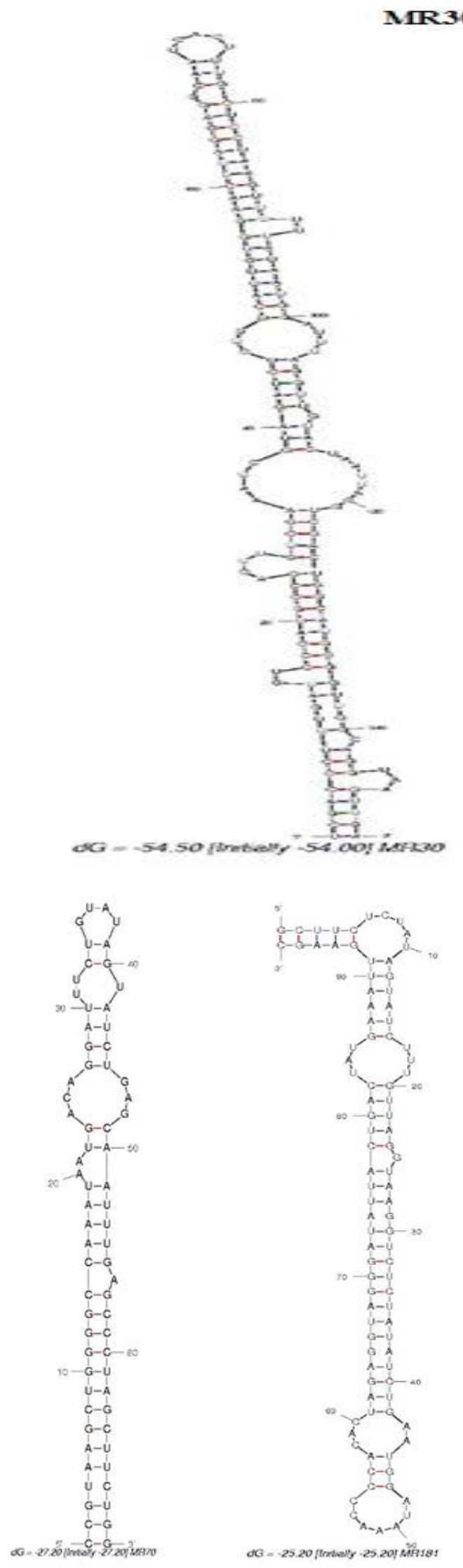




\begin{tabular}{|c|c|c|c|c|c|}
\hline Name & Sequence & (5' stem) & (3' stem) & $\begin{array}{c}\text { Mature } \\
\text { 5'stem }\end{array}$ & Mature 3'stem \\
\hline MR4 & $\begin{array}{l}\text { AGAGCAGGAUACAUAGUUUC } \\
\text { UAUCCCAAACUUAAUAGUCA } \\
\text { GGAUAAAACUGGCUAAUCCU } \\
\text { GCCUCU }\end{array}$ & $\begin{array}{l}\text { Position 3: } \\
\text { GCAGGAUACAUAGUUUCU } \\
\text { AUCC }\end{array}$ & $\begin{array}{l}\text { Position 42: } \\
\text { AUAAAACUGG } \\
\text { CUAAUCCUGC } \\
\text { CU }\end{array}$ & $\begin{array}{l}\text { Position 26: } \\
\text { AAACUUA } \\
\text { AUAGUCA } \\
\text { GGAUAAA } \\
\text { A }\end{array}$ & $\begin{array}{l}\text { Position 42: } \\
\text { AUAAAACUGGCUAAUC } \\
\text { CUGCCU }\end{array}$ \\
\hline MR13 & $\begin{array}{l}\text { CCAGUCCGUUUUUGACAUGG } \\
\text { CGUGCCUGCUCUUCUGCCAU } \\
\text { CGGCUCCAGUCGUGGGAGUG } \\
\text { GAUGGUUGGUUGGCUGGCGG } \\
\text { CUGUGUGGACCUGG }\end{array}$ & $\begin{array}{l}\text { Position 21: } \\
\text { GUGCCUGCUCUUCUGCCA } \\
\text { UCGG }\end{array}$ & $\begin{array}{l}\text { Position 58: } \\
\text { UGGAUGGUUG } \\
\text { GUUGGCUGGC } \\
\text { GG }\end{array}$ & $\begin{array}{l}\text { Position 19: } \\
\text { GCGUGCCU } \\
\text { GCUCUUCU } \\
\text { GCCAUC }\end{array}$ & $\begin{array}{l}\text { Position 58: } \\
\text { UGGAUGGUUGGUUGGC } \\
\text { UGGCGG }\end{array}$ \\
\hline MR30 & $\begin{array}{l}\text { UCGACCCUUUGAUGUCCCAU } \\
\text { GCCGACUUGUCGAAAUCGUA } \\
\text { GAUCUCUGUCAUUGUGGAAC } \\
\text { UUAGGAGGCAAUCACUUUGC } \\
\text { UCCUAAGUUUUUUAUAAUGG } \\
\text { AUUUAGGUUGUACUAAUUA } \\
\text { GGUCGACUGGCAUGGGGUUG } \\
\text { GCAGGUAAGUUGA }\end{array}$ & $\begin{array}{l}\text { Position 50: } \\
\text { AUUGUGGAACUUAGGAGG } \\
\text { CAAU }\end{array}$ & $\begin{array}{l}\text { Position 80: } \\
\text { UCCUAAGUUU } \\
\text { UUUAUAAUGG } \\
\text { AU }\end{array}$ & $\begin{array}{l}\text { Position 44: } \\
\text { UCUGUCA } \\
\text { UUGUGGA } \\
\text { ACUUAGG } \\
\text { A }\end{array}$ & $\begin{array}{l}\text { Position 80: } \\
\text { UCCUAAGUUUUUUAUA } \\
\text { AUGGAU }\end{array}$ \\
\hline MR70 & $\begin{array}{l}\text { CCGUAAGCUGGGGCCAAAUA } \\
\text { AUGACAGGAUUUCUGUAUAG } \\
\text { UAUCUGAGCAAUUUGAGCCC } \\
\text { UAGCUUCUGG }\end{array}$ & $\begin{array}{l}\text { Position 6: } \\
\text { GCUGGGGCCAAAUAAUGA } \\
\text { CAGG }\end{array}$ & $\begin{array}{l}\text { Position 44: } \\
\text { UGAGCAAUUU } \\
\text { GAGCCCUAGC } \\
\text { UU }\end{array}$ & $\begin{array}{l}\text { Position 8: } \\
\text { UGGGGCC } \\
\text { AAAUAAU } \\
\text { GACAGGA } \\
\text { U }\end{array}$ & $\begin{array}{l}\text { Position 44: } \\
\text { UGAGCAAUUUGAGCCC } \\
\text { UAGCUU }\end{array}$ \\
\hline MR181 & $\begin{array}{l}\text { GCUUCUCUAUAGUAUCUUUG } \\
\text { UUAGGUAAGGUCUCUAUAUC } \\
\text { UGAAUGGAUAAACCCCACAC } \\
\text { UAGAGGUAGGGAUAUUACU } \\
\text { GACUAUGAAAUUGAAGC }\end{array}$ & $\begin{array}{l}\text { Position 12: } \\
\text { UAUCUUUGUUAGGUAAGG } \\
\text { UCUC }\end{array}$ & $\begin{array}{l}\text { Position 60: } \\
\text { UAGAGGUAGG } \\
\text { GAUAUUACUG } \\
\text { AC }\end{array}$ & $\begin{array}{l}\text { Position 22: } \\
\text { AGGUAAG } \\
\text { GUCUCUA } \\
\text { UAUCUGA } \\
\text { A } \\
\end{array}$ & $\begin{array}{l}\text { Position 60: } \\
\text { UAGAGGUAGGGAUAUU } \\
\text { ACUGAC }\end{array}$ \\
\hline
\end{tabular}

Table no. 1: Identified miRNAs in measles and their characteristics

\section{Conclusion}

Based on integrated computational approach, we identified 5 novel miRNAs.Using different Bioinformatics' tools like NCBI, Vmir analyzer, Vmir viewer, ncRNA sequence, matureBayes ${ }^{\circledR}$ and $\mathrm{mFold}{ }^{\circledR}$ we can easily and efficiently predict the viral miRNAs. This reported miRNAs can be further used for validation in wet lab and consequently can be explored for better understanding for gene regulation.

\section{References}

[1] Scaria, V., Hariharan, M., Maiti, S., Pillai, B. \& Brahmachari, S. K. Host-virus interaction : a new role for microRNAs. 9, 1-9 (2006).

[2] Ospina-bedoya, M., Campillo-pedroza, N., Franco-salazar, J. P. \& Gallego-gómez, J. C. Bioinformatics and Biology Insights their Cellular Targets. 169-176 (2014).

[3] Vishwakarma, N. P. \& Jadeja, V. J. Identification of miRNA encoded by Jatropha curcas from EST and GSS Identification of miRNA encoded by Jatropha curcas from EST and GSS. 2324, (2017).

[4] Akhtar, M. M., Micolucci, L., Islam, S., Olivieri, F. \& Procopio, A. D. Bioinformatic tools for microRNA dissection. 44, (2016).

[5] Chilana P, Sharma A, Arora V, Bhati J, Rai A. Computational identification and characterization of putative miRNAs in Heliothis virescens. Bioinformation. 2013;9(2).

[6] Barth S, Pfuhl T, Mamiani A, et al. Epstein-Barr virus-encoded microRNA miR-BART2 down-regulates the viral DNA polymerase BALF5. Nucleic Acids Res. 2008.

[7] Cullen BR. Viral RNAs: lessons from the enemy. Cell. 2009.

[8] Bentwich I: Prediction and validation of microRNAs and their targets. FEBS Letters 2005.

[9] Pfeffer S, Sewer A, Lagos-Quintana M, Sheridan R, Sander C, Grasser FA, et al.: Identification of microRNAs of the herpesvirus fam- ily. Nat Meth 2005.

[10] Schwab R, Ossowski S, Riester M, Warthmann N, Weigel D: Highly Specific Gene Silencing by Artificial MicroRNAs in Arabidop- sis. Plant Cell 2006.

[11] Jopling CL, Yi M, Lancaster AM, Lemon SM, Sarnow P: Modulation of Hepatitis C Virus RNA Abundance by a Liver-Specific MicroRNA. Science 2005.

[12] Krol J, Loedige I, Filipowicz W. The widespread regulation of microRNA bio- genesis, function and decay. Nat Rev Genet. $2010 ; 11$.

[13] Reinhart BJ, Weinstein EG, Rhoades MW, Bartel B, Bartel DP. MicroRNAs in plants. Genes Dev 2002.

[14] Lee Y, Kim M, Han J, Yeom KH, Lee S, Baek SH, et al. MicroRNA genes are transcribed by RNA poly- merase II. EMBO J 2004.

[15] Park MY, Wu G, Gonzalez-Sulser A, Vaucheret H, Poethig RS. Nuclear processing and export of microRNAs in Arabidopsis. Proc Natl Acad Sci USA 2005.

IOSR Journal of Biotechnology and Biochemistry (IOSR-JBB) is UGC approved Journal with S1. No. 4033, Journal no. 44202.

Nivruti B. Panchal. "Computational Prediction of mi RNA in Measles virus Project Report ." IOSR Journal of Biotechnology and Biochemistry (IOSR-JBB) 03.4 (2017): 33-41. 